\title{
Clinical intervention in aging: ethicolegal issues in assessing risk and benefit
}

\author{
This article was published in the following Dove Press journal: \\ Clinical Interventions in Aging \\ I December 2010 \\ Number of times this article has been viewed
}

\section{Pierre Mallia}

Medical School, University of Malta, Mater Dei Hospital, Malta
Correspondence: Pierre Mallia Medical School, University of Malta, Mater Dei Hospital, Malta

Tel +3562340 I I 24

Email pierre.mallia@um.edu.mt
Abstract: The ethical dimension of treating the elderly, including risk-benefit analysis, focuses mainly on quality of life and end-of-life issues. These include arguments on advance directives and the concept of extraordinary treatments. This paper looks more closely at the philosophical approach to aging in order to address questions on the direction of research and issues such as longevity and social construction of the aging process. It is the way society moves to understand the value-laden choices on aging that directs the goals of treatment and research. Whilst these vary culturally, one has to reckon with a postmodern view of aging which may, in turn, reflect on the course of action of future care and research in aging. The paper canvasses how, in reality, four principles act as guidelines for moral discourse, and discusses how changing values in society decide this course of action.

Keywords: aging, principles, decision-making, conflict, treatment, clinical decision-making, social construction

\section{Introduction}

Risk-benefit analysis with or without concern for legal issues has always been the mainstay of clinical practice. Beneficence, insofar as it is a principle in medicine, has to a greater or lesser degree always been based on this issue. Even under the "accusation" that what physicians called beneficence was indeed "paternalism" (and hopefully this argument is resolved and exhausted now), whatever decisions doctors used to take was based on what in their opinion was in the patient's best interests and for the patient's good. Leaving patients ignorant of their disease and outside the realm of decision-making was considered a therapeutic privilege and done in order to "protect" the patient from news which he or she did not or should not know in order to keep them from grief which could cause them more harm than good. Times changed and so did values. The term "values" is used in order to emphasize that it is not merely a question of relativism or simply because we understand human nature better. Rather it is because Western culture cherished the concept of autonomy. It was indeed the philosophical debate which contributed considerably to increasing the "principle" (in the Kantian sense) of respecting autonomy and trumping it over beneficence, until Beauchamp and Childress ${ }^{1}$ came around to give us (or rather, lay down what was in the air) the "four principles". These evolved into an ethical framework and indeed doctors and health care providers were invoked to "use" these principles in their decision-making, calling them "mid-level" principles. Principlism came under attack ${ }^{2}$ and the defenders went on to invoke methods of using principles, such as specifying and balancing. There was not one principle to overrule the other. Specification and 
balancing were meant to address the particular situation, yet steering away from situational ethics.

Assessing risk and benefit would fall under the principle of beneficence. There is overlap also with the principle of justice because these decisions invariably also involve the use of resources that can be allocated elsewhere (without, of course, bowing to utilitarianism, as indeed even a deontologist must consider her duty to society). In the meantime, the field of gerontology and geriatric medicine has taken on new life, and rightly so; we are not only concerned with the elderly as a specific group, needing special needs with special attention to differences in medical care, just as children need a different approach to adults, but also because our populations, and perhaps cultures, are aging. ${ }^{3}$

Making decisions concerning risk-benefit for the elderly invariably therefore takes on a completely different dimension than for other adults, not only because where the elderly are concerned there is a different physiology and an aging body, but also because we are dealing with perhaps an aging culture, and more persistently so because we have to face the bottom line question: Is it worth treating this patient at this stage of life? Is it in their best interest? Is it in society's best interests? These may be blunt questions, but it is a reality from which discussions of end-of-life decision-making ensue.

The issues of cardiopulmonary resuscitation, advance directives, and research into longevity have arisen. Because we are discussing an ethical concept, and not merely a clinical algorithm, what we have at base is our attitude, in philosophical terms, towards our elderly populations. We must distinguish what is common to all and how to deal with culture. This paper is divided into three parts, with perhaps some overlap. The first discusses the reality of principles as an ethical framework and whether in essence it is our values towards the above questions which define outcomes. Secondly, it discusses three real-world situations, the third of which discusses how we view elderly in this postmodern society.

\section{Why principles and why conflict?}

Decisions are usually based on inherent cultural beliefs from which emanate virtues and general principles. Inherently we are what we are because we have learned basic concepts throughout life which set the scene for our principles. But both the use of and the foundation of these principles are inherently attached to our concept of what "is" or should be right and wrong. A difference at this level, and you invoke a different reasoning on how the same principles are used to arrive at another different answer. Indeed when we deliberate a moral problem we start with an empathic feeling of what is right and what is wrong. We then use principles in defense of this position. Rational thought about a situation may allow us to change our course of action and perhaps the final decision, but our initial value system remains essentially unchanged. Indeed, it is probable that we have conflict amongst principles because we have different value systems. Gregory Tillett perhaps best explains this conflict. ${ }^{4}$

Tillett, in his analyses of resolving conflict distinguishes three concepts, or categories, of differences between ideas, humans, relationships, and between internal (within oneself) issues, ie, problems, disputes, and conflicts. A problem can be resolved by management, ie, "by the agreement on how something can or should be done". We can easily conceive of a difficult clinical situation in which one consultant or family practitioner asks the advice of another, and doctors within a team discuss courses of action between themselves and with patients, especially within a context where there is refusal of a particular kind of treatment. Tillett points out that these problems can indeed become disputes and can generate conflict. ${ }^{4}$

A dispute occurs "when two (or more) people (or groups) perceive that their interests, needs, or goals are incompatible and they seek to maximize fulfilment of their own interests or needs, or achievement of their own goals (often at the expense of others)". Consider, for example, the situation of an elderly woman who is being taken care of at her daughter's home. This daughter has three brothers, one of whom had distanced himself from his sister due to a dispute with her husband. The main contention was that this brother convinced the others that their mother should be put in a home because he refused to visit her at their sister's home. Of course, prima facie, the best interests of the patient were for her to remain at home. However, it transpired that the woman was very depressed because this son, who was evidently her favorite, was not visiting her. The undue pressure was indeed coercive and the woman conceded to go to the home in order to be able to see all her children, not at all a voluntary choice. In the meantime she needed hospitalization. After eight months in hospital and no remedy in finding a place at an institution, the decision had to be reversed to take into consideration again her best interests, ie, avoidance of a hospital infection. Because the daughter was still willing to take her back, this course of action was taken, and the necessary legal procurements arranged. At each stage however a value-laden decision was taken, which brings us to the third category, ie, conflict.

Conflict, again as defined by Tillett, "arises when two (or more) people (or groups) perceive that their values or needs 
are incompatible - whether or not they propose, at present or in the future, to take any action on the basis of those values". Whilst problems and disputes arise within specific situations, conflicts do not need one. Two parties can be in conflict because of beliefs or because of the values they uphold, and hence the heated debates on such issues as abortion and euthanasia. But, as in the case described here, we may find that superficially, at least, the people involved had the same values in that they all loved their mother, but when it came to taking a decision which was in the best interest of their mother, it was rather a decision in their own best interests which had become evident, until a situation arose which gave enough strength to override these different values. The difference in value was between one in which $\mathrm{X}$ would rather have his mother in a home and be able to see her (and perhaps that she would be able to enjoy him), and the same person admitting that notwithstanding that his mother would not be able to see him, his sister was in a better position to take care of her and that given the state of existing homes, she may be better off. Thus a question of values and needs come in. The conflict was that between $\mathrm{X}$ and the husband of X's sister, and not the situation.

Admittedly there can be a hazy line between a dispute and a conflict, as in this case. One has to delve into the narrative of each participant in order to reveal a conflict and understand that the matter is not simply one of disputes. One can resolve the dispute and still not have handled the conflict. In this case, the brothers agreed that the mother be allowed to go to their sister's home on the condition that the sister use her pension only and not the mother's savings in order to take care of her, ie, if she needed a new bed or a commode, they were not willing to contribute to either. This coercion reveals the underlying conflict between the daughter's husband and the dominant brother, notwithstanding a resolution of the conflict. It seems that the needs or values of the children trumped the needs of the mother or the value to respect and meet her needs. Certainly this was not a dispute any more but a conflict, which unfortunately the medical practitioner or team may not be able to handle, unless by enforcing legal processes which may not be in the interests of all parties and not so conducive to conflict resolution.

Following Heraclitus, "justice is conflict". 5 Doctors make decisions in the light of beneficence and at the same time doing justice to the person(s) and the situation at hand. By "doing justice", we obviously do not merely mean that the situation is handled well and correctly (within, that is, the boundaries of standards of care), but we seek that justice is done morally. Deciding whose justice and which rationality is certainly not easy in the modern sense, especially in dealing with end-of-life situations, whether to treat or not to treat, whether to leave elderly for acute treatment at their home, or incur a more expensive, perhaps better treatment, but in a hospital setting. Certainly there can be hardly a better exposition of this philosophical reality than that put forward by MacIntyre. ${ }^{5}$ Whether he does justice to the topic is probable but whether he resolves the dilemma is uncertain. Certainly he speaks extensively of tradition, which is "an argument extended through time", in that it can be a medical tradition or a religious tradition or simply a tradition of "horse-riding". However, what is certain is that sometimes traditions come into conflict. And they come into conflict because of their values and how they view justice. Solomon ${ }^{6}$ believes that morality cannot be reduced to any strict Kantian system of principles. The very fact that the four principles of health care require further specification and balancing shows that a deeper sense of the real situation is needed, and what this usually boils down to is the narrative of the parties involved who bring forth their values and needs. Principles can help us define and understand more clearly the issues at hand Solomon does not particularly like MacIntyre's use of traditions, in the sense that it still leaves open the nostalgia for religion and a sense of community, but goes on to admit that Aristotle did invoke a sense of community when speaking about virtues. Neither does he associate virtue with feminist ethics, values not being supposed to be held captive to gender, even though feminist ethics may have a point in contrasting male principles which are hard, oppressive, and impersonal, with the female virtues of warmth and caring. Colloquially, by having principles, we are actually talking about the values a person holds as well. Principles do indeed guide, but in themselves are guided by underlying values. If one has a so-called value for life and is not in favor of euthanasia, one invokes principles to lead one to this conclusion. Conversely, if one's value system of life includes terminating suffering even by allowing physician-assisted suicide, then one will use the same four principles to reach the opposite goal.

\section{Clinical decision-making}

Having summarized the philosophical foundations on which risk-benefit analysis is based, various relevant clinical situations faced in health care are grouped. Jonsen et $\mathrm{al}^{7}$ classify three forms of disease and goals of medicine that are summarized here with particular reference to care and decisions for the elderly. These authors say that "In the first, the patient suffers from an acute illness that, once diagnosed, can be readily treated and cured. In the second, the patient experi- 
ences a process that causes serious disabilities and which, while some relief can be provided, will progress despite treatment and eventually case death. In the third, the patient suffers a chronic disease that can be effectively treated so as to relieve many of the most debilitating effects". For simplicity they use the acronyms ACURE (Acute, Critical, Unexpected, Responsive, and Easily diagnosed and treated), CARE (Critical, Active, Recalcitrant, and Eventual), and COPE (Chronic, Outpatient, Palliative, and Efficacious). Perhaps using simply "acute", "critical", and "chronic" would have been quite an accurate substitute, but these acronyms serve the purpose just as well and are applied here.

These authors point out that physicians habitually approach medical problems by attempting to determine the indications for or against medical intervention. They suggest that we face ethical dilemmas in the same way as well. In fact, assessing risk and benefit takes both medical intervention and ethical dilemmas to task, especially when considering elderly patients and when one asks oneself whether one should treat or not in a particular case. Medicine remains a science of uncertainty; even these acronyms are understood as being probability statements rather than absolute designations. Indeed, uncertainty makes for good decision-making in the face of risk-benefit analysis, and not simply one of clinical competence but also one which is value-laden.

Most goals of the medical encounter are of the first group. These goals apply to acute and relatively straightforward conditions, especially once a diagnosis has been made. The situations may be critical and unexpected, such as meningitis, reversible and easily treated (by "easy" one of course does not mean easy in the strict sense, but that one knows what to do and has an immediate plan of action based on evidencebased medicine and/or standards of care). Ethical issues in this situation may range from simply refusal of treatment to families not wishing the elderly patient to know. Recent literature suggests a more culturally sensitive approach in these clinical situations, ${ }^{8-10}$ respecting wishes which may be culturally sensitive. In Japan for example, it may be considered disrespectful to let an elderly person know of the medical condition, such that the sons and daughters take on the responsibility.

The second category (CARE) describes patients with active, progressive, and deleterious conditions. One can easily see many elderly people in such situations, although this is by no means restricted to this section of the population. Under this category lie most of the ethical dilemmas facing end-of-life decisions, such as withdrawing of life support, decisions not to intubate, decisions not to resuscitate, and irreversible coma/brain death. Advance directives are also at issue in this category. So are the mainline ethical discourses of ordinary versus extraordinary treatment, killing versus allowing to die, treating versus tender loving care, etc. These are situations that inherently carry legal issues. How would we distinguish between passive euthanasia and allowing someone to die? What is in fact ordinary and extraordinary treatment? Standards of care weigh in heavily. Even in invoking the principle of "double effect" by using high doses of morphine, for example, to treat palliatively, knowing that there is a risk that the patient may die of the dose of morphine and that this was a foreseen but unintended consequence, one must understand the nature of increasing doses of morphine and not be caught in a dispute of hastening death by going about the principle of double effect. Indeed, even though the principle has four basic rules to it, it is heavily burdened on the moral agent to ascertain that it is morally and correctly invoked (just as it takes a moral agent, for example, not to abuse the Abortion Act in the UK). There is always a standard of care in increasing dose strengths, although this is a patient-sensitive decision and hence can be externally seen as subjective.

There is no duty to treat when treatment is judged to be useless, nor a duty to treat when treatment is deemed extraordinary. Although today "proportionate" and "disproportionate" are terms which may be used instead of ordinary versus extraordinary, the latter are not only still the most commonly used terms, but they are probably the best guideline to make a judgment on risk-benefit. However, one must clearly understand the meaning of "extraordinary" to make best use of the term, and for this one must look at its original Catholic origins. Extraordinary means of preserving life are "all medicine, treatments, and operations, which cannot be obtained or used without excessive expense, pain or other inconvenience for the patient or for others, or which, if used, would not offer reasonable hope of benefit to the patient". ${ }^{11}$

A closer look at this definition shows how this covers most, if not all, legal issues that may arise when making moral choices on risk-benefit. When assessing risk, we are indeed facing the particular and singular clinical picture of this patient, including fitness for surgery, side effects and interaction of drugs, wishes of the patient, and physical state of the patient. The definition clearly does not take into account the state-of-the-art of medicine and technology, and something that is considered extraordinary today may by no means remain so tomorrow. Conversely, something that is quite ordinary treatment in one country, either because of 
culture or economic status, may indeed be extraordinary in another. Family need not be put to excessive burden, especially if they are required to pay or to go through extraordinary measures to meet the patient's needs. Clearly, where insurance and state cannot or will not pay, the family cannot morally be held responsible to take all measures necessary (in Malta, it has almost become a societal pressure to go to the UK for care when one finds no hope on the island, even if consultants say that no further treatment can be found there). Of particular note is that even medicines and excessive expense are mentioned in the definition, along with pain and inconvenience to the patient or family. Hence a treatment which cannot be afforded or which will cause prolonged agony need not be given. Therefore, we are not merely speaking of futile treatment.

The third category is that of COPE. These issues are mostly found in outpatient and community settings of family practice, and deal with the chronic and palliative. Although Jonsen et al lament that the ethical issues here may be less evident, they in fact may represent the same issues discussed above. COPE is a good acronym because in fact we are working with the patient to "cope" with the illness. Although the same goals of preserving life, preserving function, and reducing pain and suffering are used, they take on a more patient-centered approach and reach compromises with the patient that allow him or her to participate in the treatment. Whilst there may be no drama as in life-and-death situations, there is a quality-of-life perspective and also end-of-life decision-making to face. The American College of Family Physicians have recently paid much attention to helping families cope with end-of-life and also address the cultural aspects of individuals and families. ${ }^{12}$ This departs considerably from the earlier days of bioethics when autonomy meant revealing everything to the patient and almost burdening the patient with information, giving details in order to allow them to feel they were making a choice, or preferably making the choice themselves. This renewed cultural sensitivity brings back the onus on the practitioner to be truly patient-centered and to share the burden with the patient who usually indeed seeks the doctors' advice. The bigger burden lies with difficult patients, ie, those who are noncompliant and those who pose problems such as never being fully satisfied. In these situations, the doctor may be impelled to transfer the care to someone else, because a breakdown of the relationship is perceived to have occurred. Yet COPE strongly nurtures the doctor-patient relationship as well as compromise, and this may in turn translate into breakdown occurring less often. Legal issues may arise with the family, who may not be satisfied with the care imparted to their parents. However, we need to acknowledge in this regard that the involvement of the family as a community-based approach to treating the elderly is still compatible with the patient-centered approach. ${ }^{13}$

\section{Social understanding of aging}

Of course the concept of aging has changed over time. Today, with discourse on aging, one may find less difficulty with, eg, an elderly man seeking help for erectile dysfunction. Yet many bioethics committees recommend against women having fertility treatment beyond their menopausal age. With advancing technology, the right to treatments, perhaps with aging populations, will probably give ground to the yearning of the elderly spirit to continue enjoying life beyond the social boundaries thus far accepted. Leon Kass, former chairman of the US Council on Bioethics, found considerable opposition to his general wariness about reproductive technology and efforts to forestall aging. ${ }^{14}$

Therefore, risk-benefit analysis cannot look at the social concept of aging in a postmodern and perhaps posthuman society. These changes may be sudden or slow but they will occur. The concern for us now lies in making the same analysis of legality in risk-benefit not only with regard to medical care but also in terms of research, this being imperative to the advancement of medicine. We have to decide which research is moral and which not to finance with public funds. There are strong arguments for the moral imperative to research elderly subjects further, even though research in this realm is both "ethically required and ethically suspect". ${ }^{15}$ Do we carry out research in order to increase longevity, to curb the aging process, or even perhaps to stop aging all together? Whereas better cures and medical advances have already brought this out, it was never really a medical imperative. It was, at most, a welcome, although perhaps foreseen consequence of treatment and care. Yet the line is quickly drawing a distinction between a rise in the elderly population due to better survival and a deliberate search for survivorship and longevity, although such research into the genome and molecular cell biology is rapidly becoming hazy.

In discussing aging and the sociology of embodiment, Featherstone and Hepworth ${ }^{16}$ give an interesting account worth reflecting upon. At the end of the day, the body is the bottom line, when we survive to advanced old age. ${ }^{17}$ Elias, in his old age acknowledged, with an air almost of awe, that there is a "simple reality" of a finite life. ${ }^{18}$ Therefore, the "body in decline", for Featherstone and Hepworth, ${ }^{19}$ is a central issue for contemporary society to come to terms with. They assert that this does not mean that historically, when life expectancy 
was much shorter, people did not strive to prolong their life. Fear of death, intensity of bereavement, and the longing for earthly pleasures are all issues to be faced.

It is precisely in the struggle to reconstruct this cultural inheritance of pessimism that the element of difference between past and present attitudes towards aging through the later period of the life course may be found. ${ }^{19,20}$ This reconstruction, according to these social authors, lies in moving away from the pessimistic and melancholic processes of aging to one of optimism and a period enriched with distinctive creative possibilities. ${ }^{16}$ Only in this way can the structure of feeling and attitudes towards aging be changed, especially with regard to the aging body. This "social reconstruction" (or better, "change in social acceptance"), will then perhaps illuminate our attitude towards caring for our elderly in a new way and not simply as seeing them one of the "vulnerable" populations, even though they may be. We may see new light in research into the elderly and perhaps even in some form of longevity and prevention of body decline, which would bring with it a continuation of activity, be this sexual, educational, or occupational. We are already seeing countries prolong the retirement age due to improved standards of living and quality of life, and this not merely because elderly populations are on the rise and we need to continue collecting taxes from them.

In understanding our ethical and legal attitudes to the risk and benefits of treatment, we must indeed be wary therefore of any desire by groups, such as practitioners of geriatric medicine, to make claims of a specialized form of knowledge and to legitimize the imposition of controls over aging members of the population. ${ }^{21}$ One should not take this to mean that geriatric medicine should not exist, but to entail a change in concept even of the discipline itself. It need be an "advocate", much as family doctors are advocates for seeing the family more consistently in the biopsychosocial dimension, acting as family counselors and advocates for patient rights. Notwithstanding the discipline of geriatrics and the vulnerability experienced by an increased percentage of this sector of the population, we cannot continue to see old age as a form of pathology and the body in decline as a medicalized entity, which according to Katz, is an accusation often leveled at medicine. Perhaps we need to understand that the "stages" model of life is a cultural cliché, as are expressions like "ticking of the clock". 22

\section{Should we strive for technologic advancement of aging?}

"The implications for the sociology of ageing are clear: it is no longer possible to make adequate generalizations about the aging process that are grounded on biological assumptions about the ages of life. Nor is it particularly useful to adopt schemata of the life course based upon loosely conceptualized models of unspecified processes of interaction between the ontologically distinctive entities, body, self and society. As a consequence contemporary models of ageing into old age must be increasingly post-modern, by which we mean they must anticipate even more advanced forms of biocultural destabilization". ${ }^{16}$ These authors eloquently argue how our struggle is not really with biologic decline, but with the social construction of aging that has been the center of debate. Hormone replacement therapy, even if it had an element of success, was more about "remaining young and active", hidden behind the excuse of better heart and skin outcomes, until the reality of the cancer issue came to light, ie, something which many were very skeptical about from the outset. The social pressure to take hormone replacement therapy cannot be denied, in that many women may have taken it seeking a better skin complexion and less wrinkling, or at least have been encouraged to take the medication for these reasons. It is interesting that postmodern feminist studies of the interpretation of aging were associated with wisdom. Before patriarchal societies, the female crone was seen as a naturalistic and matriarchal part of life, with wrinkles being badges of honor. ${ }^{23}$ History has brought about a separation of the self from the body and society, and the seeking of youth is found at the base of this force. Whether this is the result of patriarchal influence which feminism blames is beyond the scope of this paper. The profound reality is that it is an existential issue and an entity to be reckoned with. This dualism, ie, the separation of the self from the body, lies in the very nature of the fear of aging in terms of a declining body. "If I were twenty years younger ..." is an expression that perhaps was less heard in primitive society, which adorned their elders with a wisdom and respect much less seen today. This lies at the heart and concept of the recent change towards end-of-life decision-making. Western culture is learning yet again from populations which lagged behind the materialistic taint and preserve many of their traditional values, and such is the case for Eastern countries.

There is, however, a downside to this reasoning. It lies in the nonacceptance of current culture. Featherstone and Hepworth continue to make the argument that whilst accepting the limits of the body and the aging process as having its own rewards, they adopt a negative attitude to technologic advances whereby medical intervention, such as hormone replacement therapy, is a possibility. Nowadays, in ethical circles, words like "fundamentalism" and "relativism" are 
often used in an accusatory fashion. This war of words does not reflect a dispute but a conflict. Thus, the main question would be whether hormone replacement therapy is unnatural and a threat to womanhood? Indeed, there is much sense in not seeing technology as an external factor to human nature, but as a relationship between nature and the human bodily nature (the creator of the technology itself), which is a culturally dynamic process. We have stopped seeing technology as part of our nature, because it is human nature which creates it, just as a monkey uses a stick, and perhaps moral discourse is more based on a fear of progress rather than a balancing of moral choices.

\section{Treatment and medicalization}

When seen in this light, we are be forced to accept a change in balancing risk as opposed to benefit. Whilst medicine has been attacked for being paternalistic and indeed domineering, in a Foucaultian sense, the sociology of medicine shows that the truth lies perhaps somewhere else. It is the world in general that has strived for technology and improvement of the human condition. Medicine has certainly taken advantage of new technologies for better cure rates, but research is often not carried out by "medicine" as such, but by corporations who strive to satisfy the thirst of society, and profit of course in the process. There is a delicate, and sometimes controversial, balance with cultural and religious values. Certainly we question to what extent we want technology to influence the human condition. There is nostalgia, ie, a longing to remain attached to certain roots. ${ }^{24}$ The reality of the new field of bioethics, as opposed to the centuries old Hippocratic tradition, emerged at a time when technology was also blooming.

Therefore, we may still be tied to concepts of not treating the elderly because of their age. Does one treat a 94-yearold woman who has developed breast cancer? The balance between cultural nontelling, and indeed giving a treatment adequate to what the body can withstand (it would be unwise to opt for surgery, but certainly a long-term course of tamoxifen, even if palliation is not needed) is not that difficult to conceive. However, accepting cultural criteria, such as the children of this woman, indeed in their late $60 \mathrm{~s}$ themselves, of not giving her the bad news, even if she had never explicitly expressed a wish not to know, is the morally (and perhaps legally) correct thing to do.

What is probably wrong in our approach to the elderly is to see the changing body as a pathologic process. Even if we can come to accept change in body parts, better appearance, etc, as socially acceptable, there will always be a time of reckoning with death and the human condition. Decline begins very early on in life, perhaps immediately after peak physical growth is reached. There are certainly problems that affect the elderly more, as there are problems that affect children more. Mallia and Fiorini ${ }^{25}$ have argued for separate surgical lists for the elderly to enhance "life to years" rather than "years to life". Two years for a 70-year-old is a larger proportion of one's remaining lifespan than the same number of years for a 40-year-old. Utilitarian attitudes have been carefully avoided in bioethics.

\section{Conclusion}

Certainly balancing risks and benefits may not work out in favor of the elderly person. A new social awareness towards aging helps cultivate an attitude that old age is worthwhile for what it "is" rather than for what the elderly do or what they have. Whilst looking at the risk and benefit of treatment, we cannot ignore the larger risk-benefit picture of what research and medicine hold in the future. Advanced research must be respected as part of the human need to ask, invent, and discover. However, a balance must be struck so as not to uproot people from their cultures because this is what gives people their identities. Simone Weil warns against uprooting people, cautioning that "uprootedness" leads to misery and spiritual lethargy on one hand and to violent efforts to adapt and uproot those not already uprooted.

\section{Disclosure}

The author reports no conflict of interest in this work.

\section{References}

1. Beauchamp TL, Childress JF. Principles of Biomedical Ethics. 3rd ed. New York, NY; Oxford University Press; 1989.

2. DuBose ER, Hamel R, O'Connell LJ. A Matter of Principles? Ferment in U.S. Bioethics. Valley Forge, PA: Trinity Press International; 1994.

3. Coni N, Webster S. Geriatrics. 5th ed. Oxford, UK: Blackwell Science; 2000.

4. Tillett G. Resolving Conflict. A Practical Approach. 2nd ed. Oxford, UK: Oxford University Press; 1999.

5. MacIntyre A. Whose Justice? Which Rationality? London, UK: Duckworth; 1988.

6. Solomon RC. Ethics and Excellence. Oxford, UK: Oxford University Press; 1993.

7. Jonsen R, Siegler M, Winslade WJ. Clinical Ethics. 2nd ed. New York, NY: Macmillan; 1986.

8. Searight R, Gafford J. Cultural diversity at the end-of-life: Issues and guidelines for family physicians. Am Fam Physician. 2005;71(3):515-522.

9. Crane MK, Wittink M, Doukas JD. Respecting end-of-life treatment preferences. Am Fam Physician. 2005;72(7):1263-1268.

10. Brody H, Hunt LM. Moving beyond cultural stereotypes in end-of-life decision making. Am Fam Physician. 2005;71(3):429-430.

11. Kelly G. Medico Moral Problem. St. Louis, MO: Catholic Hospital Association; 1958.

12. Lang F, Quill T, Making decisions with families at the end of life. Am Fam Physician, 2004;70(4):719-723. 
13. Wicclair MR. Ethics, community and the elderly: Health care decision-making for incompetent elderly patients. In: Parker M, editor. Ethics and Community in the Health Care Professions. New York, NY: Routledge; 1999.

14. Weiss R. Bioethics Council had to step down. Washington Post. 2005; Friday Sep 9.

15. Schafer A. Research on elderly subjects: Striking the right balance. In: Weisstub DN, Thomasma DC, Gauthier S, Tomossy GF, editors. Aging: Decision at the End of Life, International Library of Ethics, Law, and the New Medicine. Dordrecht, The Netherlands: Kluwer Academic Publishers; 2001.

16. Featherstone M, Hepworth M. Ageing, the lifecourse and the sociology of embodiment. In: Graham Scambler G, Higgs P, editors. Modernity, Medicine and Health. Medical Scoiology Towards 2000. London, UK: Routledge; 1998.

17. Woodward K. Ageing and its Discontents: Freud and Other Fictions. Bloomington, IN: Indiana University Press; 1991.

18. Elias N. The Loneliness of Dying. Oxford, UK: Blackwell; 1985.
19. Featherstone M, Hepworth M. Ageing and inequality: Consumer culture and the new middle age. In: Robbins D, Caldwell L, Day G, Jones K, Rose H, editors. Rethinking Inequality. Aldershot, UK: Gower; 1982.

20. Featherstone M, Hepworth M. Ageing and old age. Reflections on the postmodern lifecourse. In: Bytheway B, Keil T, Allatt P, Bryman A, editors. Becoming and Being Old: Sociological Approaches to Later Life. London, UK: Sage; 1989.

21. Katz S. Discipling Old Age: The Formation of Gerontological Knowledge. Charlottesville, VA: University Press of Virginia; 1996.

22. Gubrium JF. Individual Agency, the Ordinary and Postmodern Life. Milton Keynes, UK: Open University, Centre For Aging and Biographical Studies; 1995.

23. Greer, G. The Change: Women, Aging and the Menopause. London, UK: Hamish Hamilton, 1991.

24. Weil S. The Need for Roots. London, UK: Routledge; 2003.

25. Mallia P, Fiorini A. Rethinking care for the sick elderly. Maltese Medical Journal. 2003;15(1):18-20.
Clinical Interventions in Aging

\section{Publish your work in this journal}

Clinical Interventions in Aging is an international, peer-reviewed journal focusing on evidence-based reports on the value or lack thereof of treatments intended to prevent or delay the onset of maladaptive correlates of aging in human beings. This journal is indexed on PubMed Central, MedLine, the American Chemical Society's 'Chemical Abstracts Ser-

\section{Dovepress}

vice' (CAS), Scopus and the Elsevier Bibliographic databases. The manuscript management system is completely online and includes a very quick and fair peer-review system, which is all easy to use. Visit http://www.dovepress.com/testimonials.php to read real quotes from published authors. 